Bull. Mater. Sci., Vol. 22, No. 4, June 1999, pp. 811-815. (C Indian Academy of Sciences.

\title{
Characterization of reinforced syntactic foams using ultrasonic imaging technique
}

\author{
C S KARTHIKEYAN, C R L MURTHY ${ }^{\dagger}$, S SANKARAN" and KISHORE* \\ Department of Metallurgy, ${ }^{\dagger}$ Department of Aerospace Engineering, Indian Institute of Science, Bangalore 560012 , \\ India \\ "Aeronautical Development Establishment, C V Raman Nagar, Bangalore 560 093, India
}

MS received 9 February 1999; revised 26 April 1999

\begin{abstract}
Non-destructive evaluation of defects like voids in syntactic foam reinforced with epoxy compatible chopped strand glass fibres, employing ultrasonic C-scan immersion through transmission method, was undertaken. The results showed that in four of the five similarly processed foam samples, the voids were uniformly spread while in the fifth, which was processed by a different route, a large spread of low dense area was noticed emphasizing the influence that processing technique has on the amount of voids present in the composites.
\end{abstract}

Keywords. Syntactic foam; voids; non-destructive testing; sandwich structure.

\section{Introduction}

Mechanical properties are considerably affected by the presence of defects or damages in a structure. Therefore, it becomes necessary to evaluate the material for the presence of such features prior to its usage so that an effective mapping and thereafter screening of the component for the presence of defective regions can be done. For this purpose, non-destructive evaluation (NDE) is widely and very effectively used. This evaluation for the case of homogeneous materials has, for the past several decades, been concerned with detection, sizing, and determination of the orientation of defects and single cracks.

NDE of composite materials has only recently been gaining attention. However, many different non-destructive testing (NDT) techniques (Henneke 1990) have been developed which can detect most defects and damages known to be present in composite materials. Ultrasonics (Bray and Stanley 1989) is perhaps the most widely used test method for evaluation of composites as it is sensitive to the presence of porosity, matrix crazing and cracking and delaminations. Hence, in the present work, it was decided to examine the effectiveness of this method for detection of voids in the case of newer composite system, viz. reinforced syntactic foams.

Syntactic foams (Malloy and Hudson 1990) are composite foam materials that in most cases consist of preformed hollow glass, ceramic, or polymeric spheres dispersed within a polymer matrix or binder. The compositions and densities of syntactic foams are predictable, since these unique foams are constructed by filling mechanically the gas containing particles into the matrix rather than being produced by

\footnotetext{
*Author for correspondence
}

conventional foaming agents. Hence these are also known as physical foams (Shutov 1981). Since they are formally similar in structure to cellular gas-expanded plastics, in that they are heterophase gas-solid systems, they are also classified along with foamed plastics (Deanin 1996). On the basis of their structure syntactic foams are classified as either a two-phase or a three-phase system (Price and Nelson 1976). In most cases, syntactic foams have mechanical properties, for instance the specific strength, superior to conventional polymeric foams. However, they are likely to have higher densities unlike the conventional ones. Since the processing is mechanical, the entrapment of some amount of air leading to voids is inevitable. It is well known that the presence of voids affects the mechanical properties considerably. Hence it is required to delineate the regions in the sample where voids are present and thereafter discard the same so that the sound part can be used for carrying out the assessment of mechanical properties. Nondestructive evaluation, in particular the ultrasonic method, is very helpful in this regard.

These syntactic foams find application as subsea buoyancy materials (Seamark 1991). It is necessary to characterize the core to have a better understanding of the sandwich structure. And since syntactic foams have found use as a core material in construction of sandwich structures (Hiel et al 1993), a programme (Nikhil Gupta et al 1998) was earlier evolved to characterize the core, unreinforced syntactic foam, and the sandwich material. This work is an effort in continuation except that glass fibres in the form of chopped strands were used, in addition to microballoons, as reinforcement for syntactic foam. The technique selected was ultrasonic C-scan through transmission immersion method, as pulse-echo method was found insensitive for such materials. This NDE approach, it is felt, will serve as an effective 
prequalification prior to destructive testing for overall properties evaluation of these foams.

\section{Experimental}

\subsection{Materials}

Epoxy resin system consisting of Epoxy Novolak resin (LY5052) and hardener cycloaliphatic polyamine (HY5052) supplied by Hindustan Ciba-Geigy was used. Resin and hardener were mixed in $100: 38$ ratio by weight. The density of the cured resin system was $1.15 \mathrm{~g} / \mathrm{cc}$. Glass hollow microspheres (called microballoons), Ecospheres SI (supplied by Grace Electronic Materials, Belgium), with diameter in the range $10-100 \mu \mathrm{m}$ and density $0.25 \mathrm{~g} / \mathrm{cc}$, were used as a closed pore material. Epoxy system compatible E-glass fibres in the form of chopped strands of length $6 \mathrm{~mm}$ (supplied by FGP India Ltd.), were used for incorporation into syntactic foam.

\subsection{Processing}

Reinforced syntactic foams were processed with varying weight fractions of fibres (in resin) keeping the volume fractions of resin and microballoons constant. Glass fibres were introduced into a beaker that contained the required quantity of resin heated to $70^{\circ} \mathrm{C}$. The resulting mixture was stirred well for uniform dispersion of the chopped fibres. The system was allowed to cool to room temperature. The specified quantity of hardener based on the resin-to-hardener ratio mentioned earlier was mixed and stirred well. At this stage weighed quantity of microballoons, in several lots, was added to the system containing resin mix and fibres, stirring the contents well each time. Mixing was gentle to avoid breakage of microballoons till the mix developed as a dough. The dough was filled manually into a metallic mould of dimension $150 \mathrm{~mm} \times 150 \mathrm{~mm} \times 25 \mathrm{~mm}$. The mould was then closed and allowed to cure for 18-24 h at ambient temperature. This procedure enabled avoidance of resin matrix flow if initial higher temperatures were chosen. Hence it was decided to cure the foam slabs at room temperature for $18-24 \mathrm{~h}$ and adopt a post-curing step for $150 \mathrm{~min}$ at $130^{\circ} \mathrm{C}$ to attain the required mechanical properties. The above procedure was followed for making four syntactic foam slabs containing $5,10,15$ and $25 \mathrm{wt} \%$ of fibres in resin.

For the $20 \mathrm{wt} \%$ of fibre in resin-bearing situation, the following procedure was adopted. The required quantity of resin and hardener was taken in a beaker and stirred mechanically. The weighed quantity of microballoons was added, in several lots to the resin system, stirring the contents well each time. To this glass fibres were added and mixed well to get a dough form. In other words, in the first case involving making of four slabs, the fibres were added initially while in the fifth case fibres were introduced at the end. How this procedural difference affects the extent to which voids appear in the cast slab and thereafter its detection by NDT constituted the prime purpose of this study.

\subsection{Equipment and technique}

As the volume occupied by air in syntactic foam is larger, ultrasonic waves are highly absorbed by the material. It was therefore not possible to use the highly popular pulseecho method. Hence through transmission method was adopted where the path travelled by the sound beam inside the material is half compared to the pulse-echo method. Consequently the intensity of the signal received by the receiving probe is higher.

For the present work a 3-inch point focused probe of $5 \mathrm{MHz}$ frequency was used. This selection was based following several unsuccessful attempts with other probes. Water was used as the immersion medium in the present experiment. The RF signal showing different regions of attenuation was displayed on the oscilloscope. Planar scanning at a given depth known as C-scan was adopted to scan the material. In this technique the material is indexed on one axis and scanned on the other principally for estimating the change in density, which is measured in terms of attenuation in $\mathrm{dB}$ units. The equipment was a microprocessor-operated and controlled system. Movement of probes on all the three axes was through stepper motors and was operated by a built-in software. The information thus obtained is converted and presented in colour code (pseudocolouring). Ultran NDC-7000 was used to obtain the scanned images. The scanning of the foams were done in two sections. Although the full section of the sample was scanned, the $\mathrm{C}$-scan images presented here correspond to one half section only.

\section{Results and discussion}

Focused probes (Touffait et al 1980) in ultrasonic inspection assist in detecting, imaging and sizing of flaws owing to their better resolution. Figure 1 shows a C-scan image of the reinforced syntactic foam slab containing 5\% by weight of fibre in resin. The image displays fairly uniform colours (white and red) along with blue colour attributed in this work to the voids being uniformly spread. Figure 2 shows the $\mathrm{C}$-scan image of syntactic foam slab with $10 \mathrm{wt} \%$ fibre bearing foam. Even here the distribution is fairly uniform except for small voidbearing region (represented by blue code) showing more attenuation of ultrasonic waves. The C-scan image of syntactic foam with $15 \mathrm{wt} \%$ fibre (figure 3 ) is relatively better than the previous one (figure 2) as regards the presence of voids. In figure 4 is shown the C-scan image of syntactic foam slab containing $25 \mathrm{wt} \%$ of fibre, wherein regions of both smaller and larger attenuation of ultrasonic energy can be seen. It is clear that compared to other three samples discussed earlier, this sample has more voids. There is no direct relationship between volume fraction of fibres and void content as the volume fraction of fibres added is very small ranging from $0.90-4.5 \%$. Void entrapment in these foams, on the other hand, is a result of the mixing conditions and the wetting of fibres and microballoons by the 
matrix material. In fact the void volume fraction in these foams ranges between 6 and 10.5\%.

Figure 5 is the C-scan image of syntactic foam with $20 \%$ by weight of fibre in resin. This picture shows a larger region of greater attenuation (central portion) indicating low density. Compared to other four samples this sample has greater degree of voids. As a result of mixing sequence and conditions adopted in the processing of the foams bearing $20 \mathrm{wt} \%$ of fibres being different, they have larger distribution of less dense regions. This resulted in higher attenuation values as seen in figure 5 . Figures $1-4$ have less of greater attenuation areas than figure 5 implying the fifth slab is less dense compared to the other four samples. This would be reflected in the mechanical property of this foam. Thus the modification of the processing at the fabrication stage of the foam slabs has a

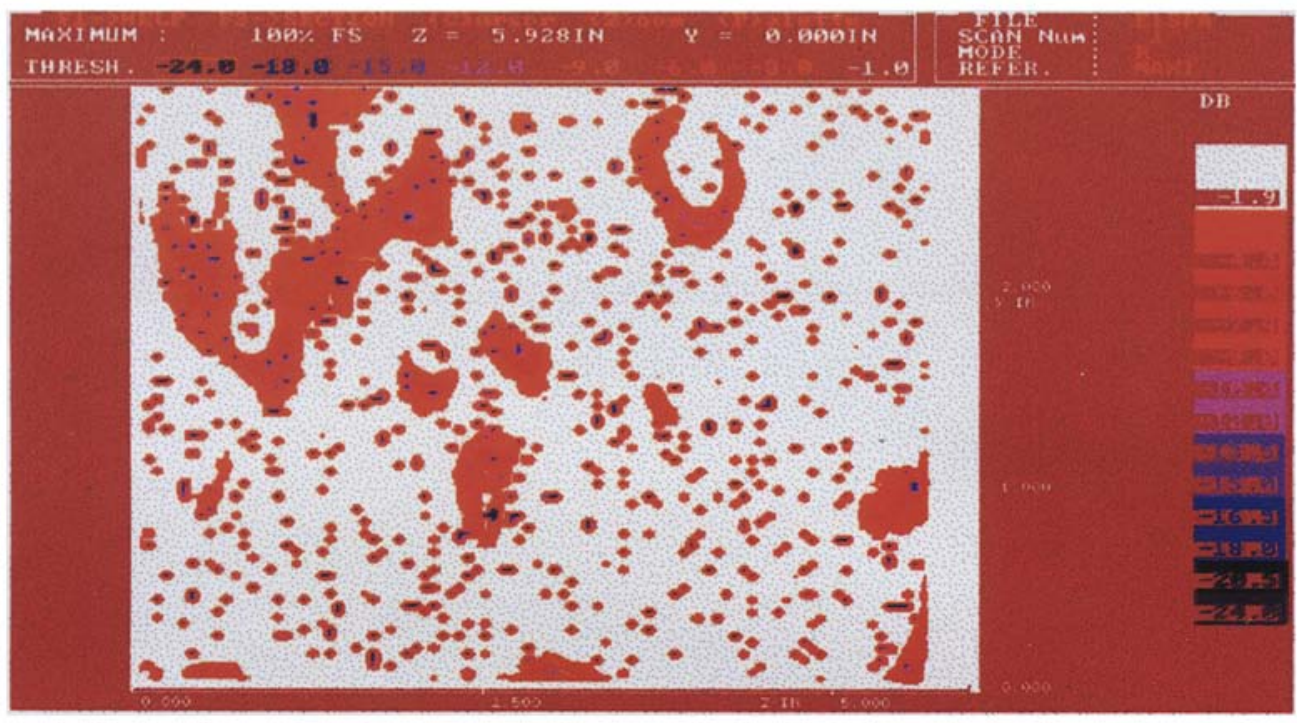

Figure 1. C-scan image of the reinforced syntactic foam (RSF) containing $5 \mathrm{wt} \%$ of fibre in resin.

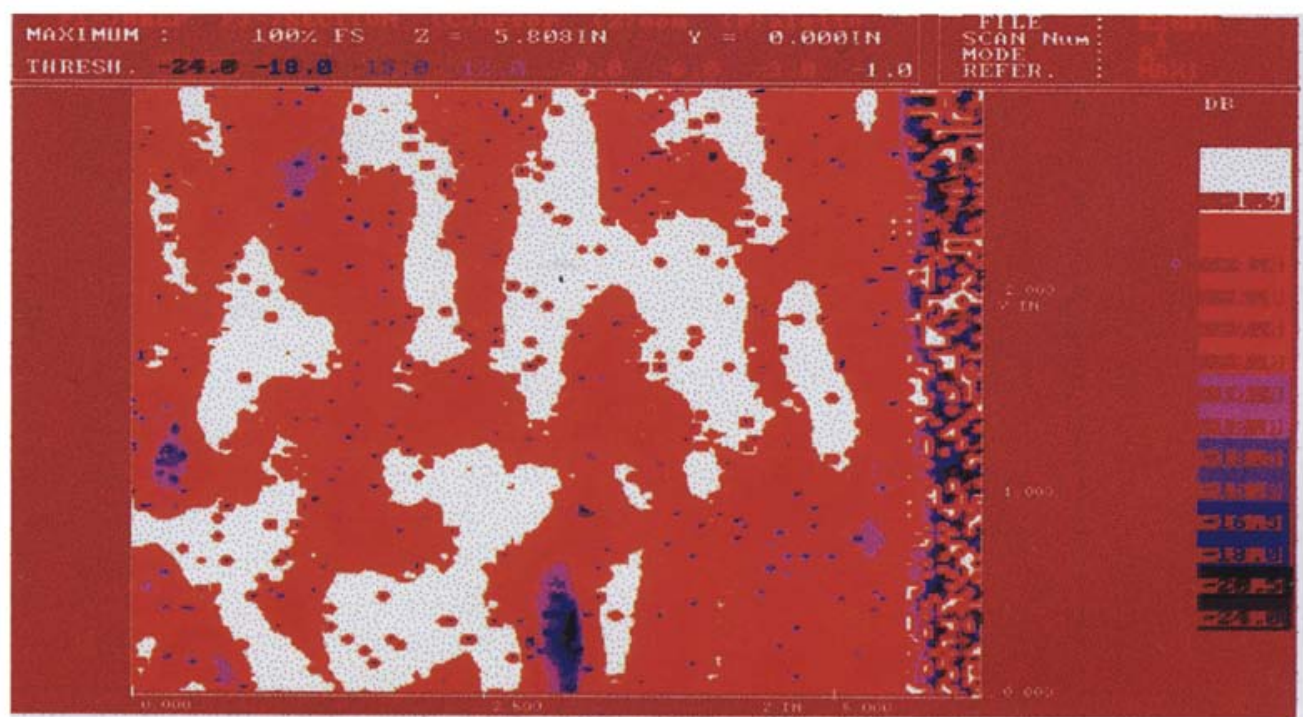

Figure 2. C-scan image of the RSF bearing 10 wt\% of fibre in resin. 


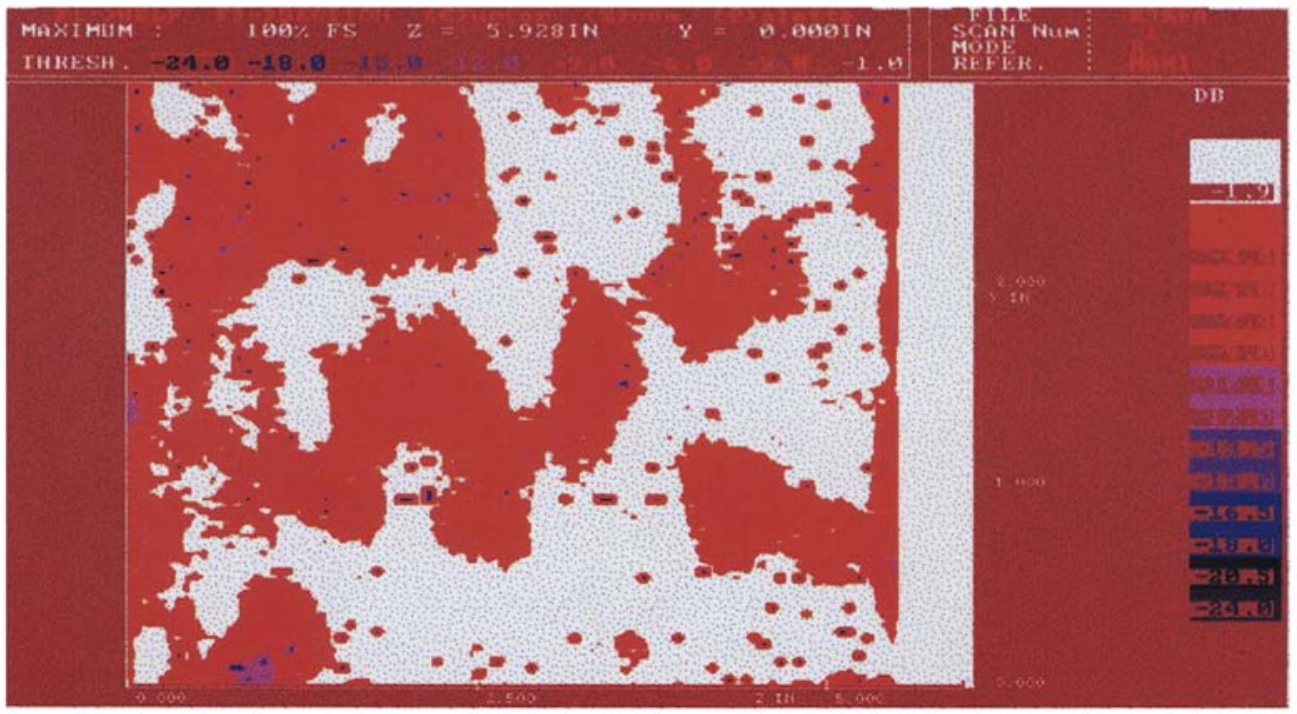

Figure 3. C-scan image of RSF containing 15 wt $\%$ of fibre in resin.

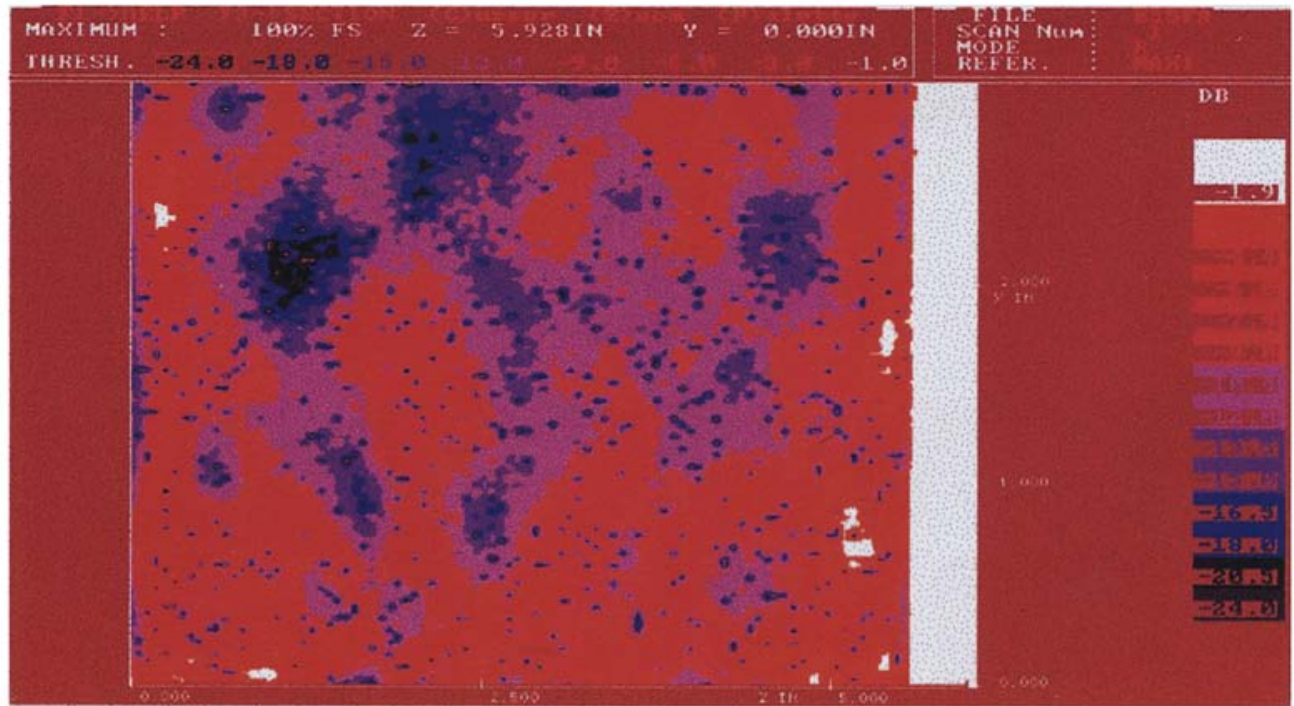

Figure 4. C-scan image of RSF containing 25 w1\% of fibre in resin.

bearing on the extent of spread of voids, which is clearly seen in the $\mathrm{C}$-scan images of the reinforced syntactic foams.

\section{Conclusions}

The present results lead to the following conclusions. Through transmission ultrasonic $\mathrm{C}$-scan method can be used to monitor the extent of occurrence of voids in reinforced syntactic foams. It was possible to delineate the void-bearing regions from an analysis of the results. The work also unambiguously shows that effecting a change in the procedure during casting of the syntactic foam slabs brings about a noticeable change in the level/distribution of the voids. This clearly demonstrates the utility of this technique as a prequalification test procedure before the mecha- 


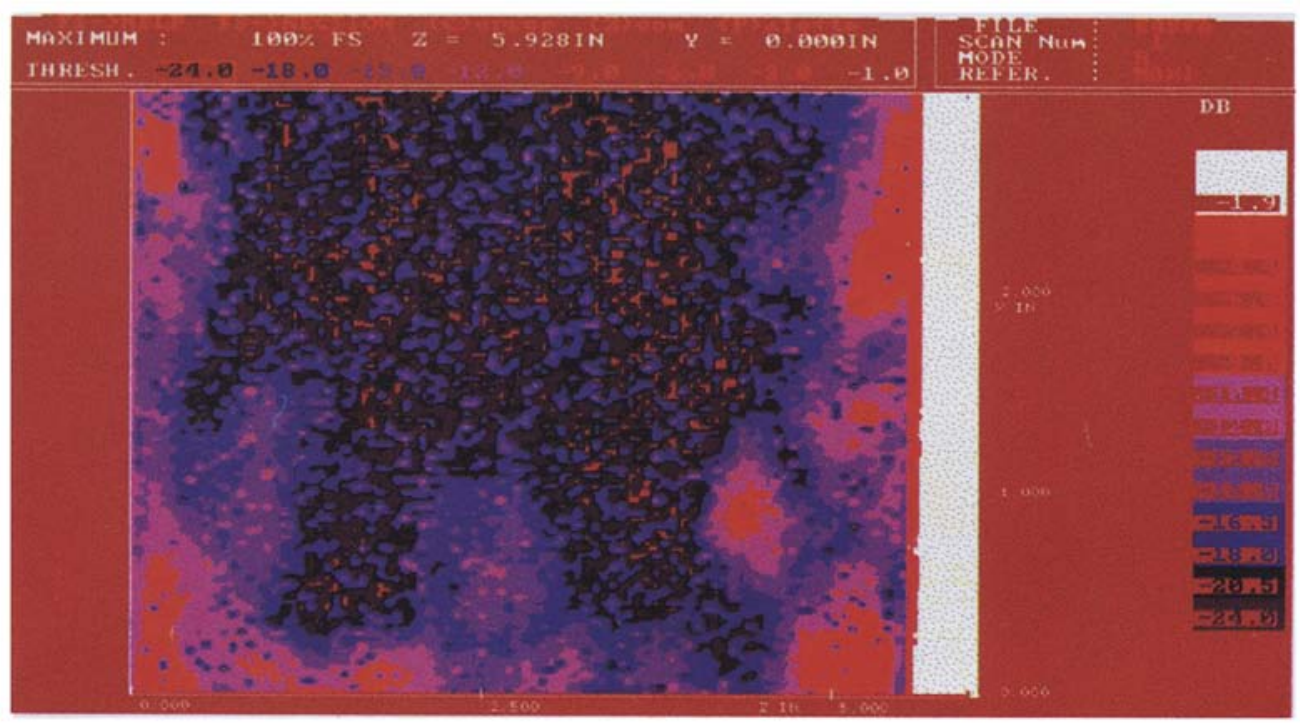

Figure 5. C-scan image of RSF having $20 \mathrm{wt} \%$ of fibre in resin.

nical properties of the composite slabs can be evaluated.

\section{Acknowledgements}

The authors are grateful to the Chairman, Department of Metallurgy, Indian Institute of Science, and the Director, Aeronautical Development Establishment, for support extended all through the work. CSK is indebted to $\mathrm{Mr}$ M N Jagadish Kumar and Mr Govindaraju of Aeronautical Development Establishment for help in fabrication of the samples and to Ms D Anuradha of Department of Aerospace, Indian Institute of Science, for assistance in scanning experiments.

\section{References}

Bray D E and Stanley R K 1989 Nondestructive evaluation (New York: McGraw Hill)
Deanin R D 1996 in Polymeric materials encyclopedia (ed.) Joseph C Salamone (New York: CRC Press) Vol. 4, p. 2554

Henneke E G 1990 Proceedings of the Indo-US workshop on composites for aerospace application, part l, (ed.) J N Reddy, Department of Aerospace Engineering, Indian Institute of Science, Bangalore, pp. 41-68

Hiel C, Dittman D and Ishai O 1993 Composites 24447

Malloy R A and Hudson J A 1990 International encyclopedia of composites (ed.) S M Lee (New York: VCH Publishers) Vol. 1, p. 257

Nikhil Gupta, Anuradha D, Murthy C R L, Sankaran S and Kishore 1998 J. Non-Destruct. Eval. 1927

Price H J and Nelson J B 1976 J. Compos. Mater. 10314

Seamark M J 1991 Cellular Polym. 10308

Shutov F A 1981 Adv. Polym. Sci. 391

Touffait A M, Destribats M T, Roule M and Saglio R 1980 in Proceedings of the first international symposium on ultrasonic materials characterization (eds) $\mathrm{H}$ Berger and $\mathrm{M}$ Linzer NBS Spl. Pub. 596, p. 257 